\title{
Answers to self-assessment questions
}

1. $\mathrm{A}$ - true, $\mathrm{B}$ - true, $\mathrm{C}$ - false: $2-10$ weeks, $\mathrm{D}$ - true, $\mathrm{E}$ - true.

2. A-false: they would benefit from alcohol education, $\mathrm{B}$ - true, $\mathrm{C}$ - false: it is more focused on immediate implementation of change, $\mathrm{D}$ - true, $\mathrm{E}$ - true.

3. A - true, $\mathrm{B}$ - false, $\mathrm{C}$ - false: the amount is not a criterion however a person drinking large amounts is more likely to be dependent, $\mathrm{D}$ - false: this is a DSM IV criterion, $\mathrm{E}$ - true.

4. All answers are true.

5. A - false: they are not yet aware of a problem, B - false, C-true, D-false, E-false: maintenance is the final stage.

6. A-true, B - false: hypertension, C-true, D-false: visual hallucinations are more likely, E- false: this a feature of Wernicke's encephalopathy.

7. $\mathrm{A}$ - true, $\mathrm{B}$ - true, $\mathrm{C}$ - false, $\mathrm{D}$ - false, $\mathrm{E}$ - false.

Prepared by Raveen Hanwella, Department of Psychological Medicine, Faculty of Medicine, Colombo, Sri Lanka.

E-mail <raveenhanwella@yahoo.co.uk>. 